\title{
THE SOLAR HEAT LOAD: ITS RELATIONSHIP TO TOTAL HEAT LOAD AND ITS RELATIVE IMPORTANCE IN THE DESIGN OF CLOTHING ${ }^{1,2}$
}

\author{
By HAROLD F. BLUM \\ (From Naval Medical Research Institute, National Naval Medical Center, Bethesda, Maryland)
}

(Received for publication March 17, 1945)

This study was undertaken to estimate the relative effect of clothing in protecting men exposed out-of-doors from the heat load contributed by sunlight. Under such conditions, sunlight, both direct and reflected, forms a certain portion of the total heat load. This will be referred to herein as the solar heat load. If the influence of clothing on the total heat load is to be analyzed, this factor is best treated as separate from the heat load contributed indirectly by the sun through its influence on the temperature of the ambient air and the terrain.

The evaluation of the effect of clothing on the solar heat load by direct experimental methods presents many difficulties. Sunlight cannot be closely simulated in the laboratory and, on the other hand, testing under outdoor conditions presents difficulties because numerous factors cannot be accurately evaluated and controlled.

\section{THE SOLAR SPECTRUM}

In order to view the problem properly, reference must be had to the spectrum of sunlight. Curve 0 in Figure 1 represents the spectral distribution of sunlight outside the earth's atmosphere. The spectral distribution is altered in passage through the atmosphere due to the fact that all wave lengths are not absorbed equally. The atmospheric constituents chiefly responsible for this alteration of the spectrum are ozone, which absorbs the short wave length ultraviolet end of the spectrum, and water vapor which absorbs the long infrared wave lengths. The latter is of particular importance with regard to the present problem. The quantities of both ozone and water vapor in the atmosphere vary at different times

\footnotetext{
1 The opinions or assertions contained herein are the private ones of the writer, and are not to be construed as official or reflecting the views of the Navy Department.

2 This paper was originally prepared as a report for the Subcommittee on Clothing of the National Research Council.
}

and places, and the spectral distribution of sunlight is altered accordingly. The other gases in the atmosphere absorb very little within the spectral range of sunlight. The spectral distribution is also altered by scattering by gas molecules, and by dust particles. Curves 1 and 2 in Figure 1 represent sunlight at the earth's surface when certain quantities of ozone $(2.8 \mathrm{~mm}$.), water vapor (20 mm.), and dust (300 particles per $\mathrm{cm}^{3}$ ) are present in the atmosphere. Curve 1 represents the spectrum when these atmospheric conditions pertain and when the sun is directly overhead, while curve 2 represents the spectrum under the same conditions when the sun is $60^{\circ}$ from zenith, at which time the rays pass through twice as thick a layer of atmosphere:

Considering all these factors, it is obvious that accurate predictions cannot be made about sunlight without direct measurements, or without knowledge of the atmospheric conditions and proper consideration of latitude, season, and time of day, all of which determine the angle of the sun with respect to the zenith.

Figure 1 shows that the maximum of the solar spectrum occurs at about $0.48 \mu$. Thermal emission having its maximum at this wave length would be given off by a black body at $6,000^{\circ} \mathrm{K}$. (K. = Kelvin, absolute temperature). Such a temperature is not attainable in the laboratory for a mass great enough to supply quantities of radiant energy comparable to sunlight. This presents an apparently insurmountable barrier to the simulation of sunlight in the laboratory.

The curves $R$ and $C$ in Figure 1 indicate the spectral sensitivity of, respectively, scotopic vision (rods) and photopic vision (cones). The latter covers the approximate range $0.4 \mu$ to $0.7 \mu$. This is generally referred to as the visible spectrum, shorter wave lengths being denoted ultraviolet, and longer wave lengths infrared. Measurements in which the human eye is used as the photo- 


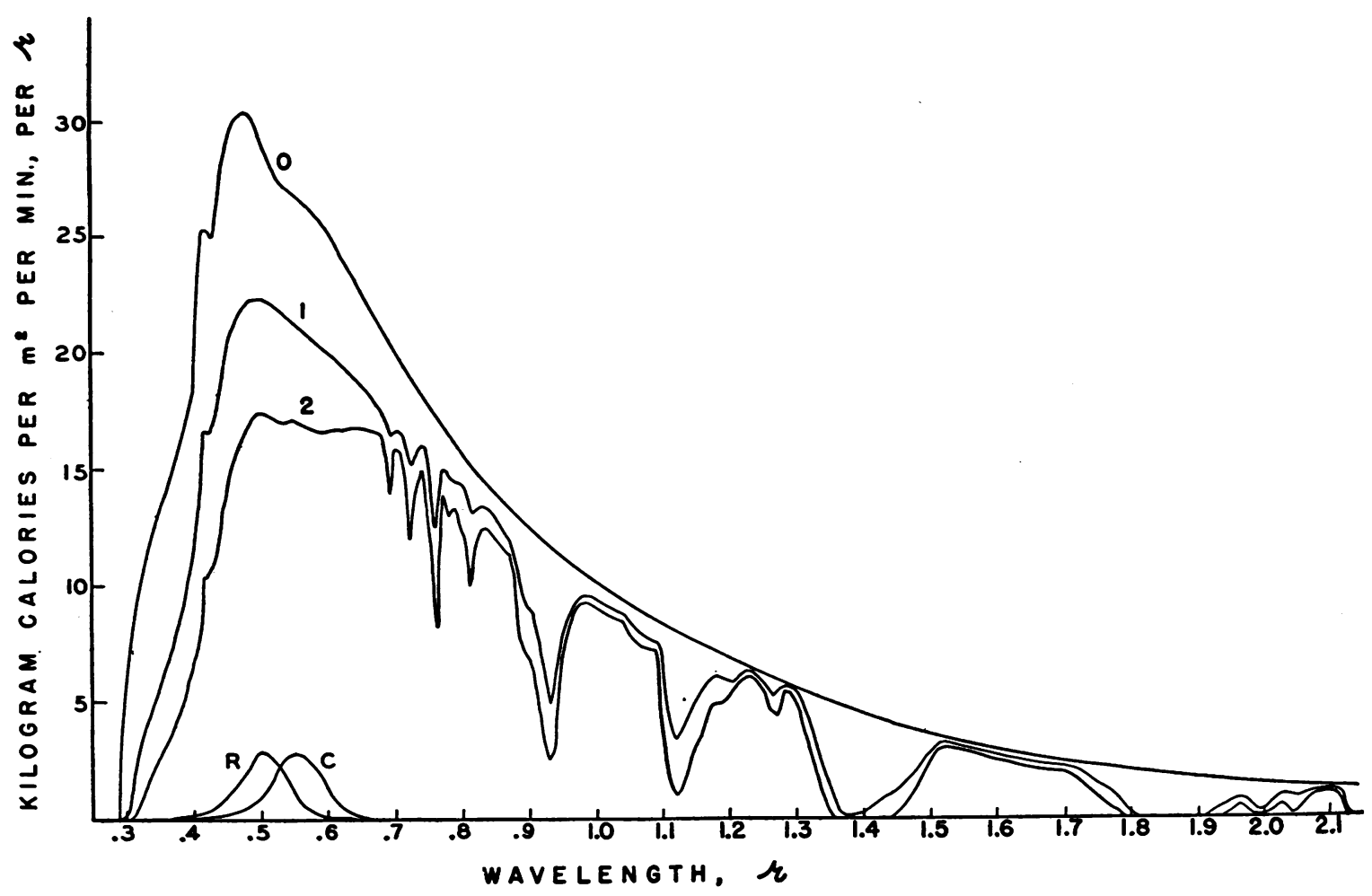

Fig. 1. Spectral Distribution of Sunlight

0 , outside the atmosphere; 1 , with the sun at zenith; 2 , with the sun at $60^{\circ}$ from zenith. Curves 1 and 2 are for $20 \mathrm{~mm} . \mathrm{H}_{2} \mathrm{O}, 2.8 \mathrm{~mm}$. ozone, and 300 dust particles per $\mathrm{cm}^{3}$ From the data of Moon (1).

Curves $\mathrm{R}$ and $\mathrm{C}$ indicate, respectively, the spectral sensitivity of the human rods, and cones; the ordinate units are arbitrary.

sensitive instrument (this includes all "photometric" measurements) give inaccurate information as to the intensity of the ultraviolet or infrared radiation or of total sunlight.

In the present problem we are concerned with the heat load contributed by sunlight, which is made up of wave lengths ranging from approximately $0.29 \mu$ to $2.2 \mu$. A certain portion of the radiation falling upon the body is absorbed, and the remainder reflected. If the body were covered with a surface which reflected a large proportion of all these wave lengths, as for example, with aluminum paint, the solar heat load might be reduced to a negligible quantity. White clothing would reduce the load, but camouflage requirements for military clothing limit the amount of sunlight that can be reflected in certain regions of the spectrum, for a part of the visible spectrum must be absorbed in order that a man may appear to blend into the terrain. Thus, any attempt to improve the reflecting power of clothing must be limited by the requirements of camouflage so far as visible wave lengths $(0.4 \mu$ to $0.7 \mu)$ are concerned. Since photographic reconnaisance using infrared sensitive photographic emulsions must be considered also, similar restrictions are placed on the amount of reflection allowable in the near infrared, to which these emulsions are sensitive. If the more common infrared sensitive emulsions are used, the long wave length limit is about $0.9 \mu$; if it is possible to use the most sensitive emulsions, this must be extended to $1.2 \mu$. In Table I the amounts of solar radiant energy falling on a horizontal surface are shown for various spectral regions for different conditions.

\section{REFLECTION OF SUNLIGHT FROM FABRICS}

Aldrich has recently measured the reflection of sunlight by a number of fabrics. His measurements, quoted by Wulsin (2), are reproduced in 
TABLE I

Energy of sunlight ${ }^{1}$

\begin{tabular}{|c|c|c|c|c|}
\hline \multicolumn{5}{|c|}{ Energy of sunlight } \\
\hline \multirow[b]{2}{*}{$\begin{array}{c}\text { Zenith } \\
\text { angle }\end{array}$} & \multirow[b]{2}{*}{$\begin{array}{c}\text { All wave } \\
\text { lengths }\end{array}$} & \multicolumn{3}{|c|}{ Kilocalories per $\mathrm{m} .^{2}$ per minute } \\
\hline & & $\begin{array}{c}\text { Exclusive of } \\
\text { visible } \\
\text { (all except } \\
0.4 \mu \text { to } 0.7 \mu \text { ) }\end{array}$ & $\begin{array}{c}0.7 \mu \text { to } \\
0.9 \mu\end{array}$ & $\begin{array}{c}0.9 \mu \text { to } \\
1.2 \mu\end{array}$ \\
\hline $\begin{array}{r}0^{\circ} 2 \\
0^{\circ} 3 \\
60^{\circ} 3\end{array}$ & $\begin{array}{l}14.7 \\
13.2 \\
10.6\end{array}$ & $\begin{array}{l}8.7 \\
7.3 \\
5.9\end{array}$ & $\begin{array}{l}5.0 \\
3.9 \\
3.3\end{array}$ & $\begin{array}{l}2.7 \\
1.9 \\
1.5\end{array}$ \\
\hline
\end{tabular}

1 Estimated from the data of Moon (1).

2 Dry air, $2.8 \mathrm{~mm}$. ozone, 300 dust particles per $\mathrm{cm}^{3}$.

$820 \mathrm{~mm}$. $\mathrm{H}_{2} \mathrm{O}, 2.8 \mathrm{~mm}$. ozone, 300 dust particles per $\mathrm{cm}^{3}$.

Table II, together with a few older measurements (3). Earlier measurements by Coblenz (4) are in general agreement with these, but refer to only limited portions of the spectrum. Aldrich's data include measurements of transmission of sunlight by the fabrics, which in no instance is high. It may be assumed that most of the transmitted radiation is eventually absorbed either at the skin surface or by the fabric, so it has been included in the percentage contributing to the heat load in the first column of Table II.

TABLE II

Reflection of total sunlight by various fabrics

\begin{tabular}{|c|c|c|c|c|}
\hline Item & Fabric & $\begin{array}{l}\text { Con- } \\
\text { trib- } \\
\text { uting } \\
\text { to the } \\
\text { heat } \\
\text { load }^{1}\end{array}$ & $\begin{array}{c}\text { Re- } \\
\text { flected }\end{array}$ & $\begin{array}{l}\text { Trans- } \\
\text { mitted }\end{array}$ \\
\hline $\begin{array}{r}2 \\
3 \\
4 \\
5 \\
6 \\
7 \\
8 \\
9 \\
10\end{array}$ & $\begin{array}{l}\text { Data of Aldrich } \\
\text { Shirt, Mock Leno, slightly } \\
\text { permeable } \\
\text { Cotton, khaki-8.2 oz. } \\
\text { Cotton, percale, white } \\
\text { Cotton, percale, O.D. } \\
\text { Cotton, tubular balbriggan } \\
\text { Cotton, twill, khaki } \\
\text { Cotton, shirting worsted, } \\
\text { O.D. } \\
\text { Cotton denim, blue } \\
\text { Cotton, herringbone twill } \\
\text { Cotton, duck No. } 746 \\
\quad \text { Data of Martin (3) } \\
\text { Cotton shirt, white un- } \\
\text { starched, 2 thicknesses } \\
\text { Cotton shirt, khaki } \\
\text { Flannel suiting, dark gray } \\
\text { Dress suit }\end{array}$ & $\begin{array}{l}55.9 \\
43.7 \\
33.2 \\
51.5 \\
37.6 \\
48.3 \\
\\
61.1 \\
67.4 \\
73.7 \\
92.8\end{array}$ & $\begin{array}{r}44.1 \\
56.3 \\
66.8 \\
48.5 \\
62.4 \\
51.7 \\
\\
38.9 \\
32.6 \\
26.3 \\
7.2\end{array}$ & $\begin{array}{l}5.1 \\
0.0 \\
0.5 \\
2.5 \\
3.2 \\
0.2 \\
\\
0.1 \\
0.0 \\
0.1 \\
0.0\end{array}$ \\
\hline
\end{tabular}

1 The transmitted radiation is considered to be absorbed by the skin (see text).
There is considerable difference in reflection by the different fabrics. As would be expected, white fabrics reflect more than colored fabrics, but the total reflection need not parallel too closely the apparent darkness to the eye. Aldrich has estimated the per cent of radiation reflected in the "visible" $(0.3 \mu$ to $0.7 \mu)$ and in the "infrared" $(0.7 \mu$ to $2.5 \mu)$, for the items described in Table II, and these data are reproduced in Table III. In general, these fabrics reflect infrared radiation to a greater extent than visible. This is contrary to a widespread, erroneous belief that all substances absorb infrared radiation almost completely.

TABLE III

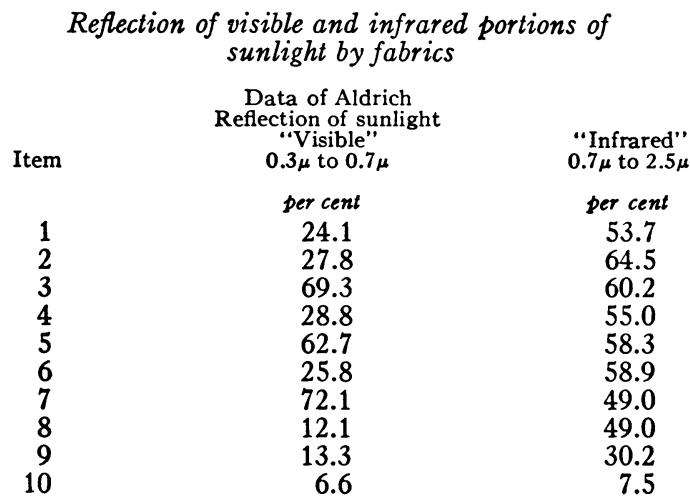

Improvement of the reflecting power of clothing within the limits imposed by military field requirements would depend chiefly upon finding dyes which, while presenting appropriate colors to the eye (or contrasts to the photographic emulsion) compatible with camouflage requirements, permit greatest reflection of the total radiation. This would entail mainly the reflection of infrared radiation. Texture of the fabrics is also of importance, since some will be better diffuse reflectors than others. These will probably be minor factors, however, and the absorption spectra of the dyes can be regarded as placing the limits of attainable reflection. The absorption spectra of dyes, and hence their reflecting properties, depend upon their chemical constitution. As a rule they do not give sharp spectral cut-offs. It would probably be difficult to predict the appropriateness of particular dyes without laborious study of their absorption spectra, including ranges outside the scope of the usual spectrographic equipment. 
Thus, the selection of dyes to improve the reflecting powers of military fabrics would be a difficult task, and the degree of success to be expected is not great.

Under the field conditions, clothing becomes soiled and this may alter both the total reflection and the reflection in different spectral regions.

\section{REFLECTION BY HUMAN SKIN}

The reflection of sunlight by human skin provides a basis of comparison with the reflection by fabrics. Martin (3) found 43 per cent reflection of total sunlight from average blond human skin. Brunet skin showed 35 per cent reflection, and negro skin 16 per cent. The values for white skin are in general agreement with those of another investigator (5) for reflection of total sunlight, and compatible with those of others who have measured the reflection of visible, ultraviolet, and infrared wave lengths $(6,7,8)$.

\section{THE SOLAR HEAT LOAD AND ITS RELATIVE IMPORTANCE}

The total solar heat load, $L$, impinging upon a man exposed directly to the sun may be divided into 3 portions: $D$, the direct radiation which strikes the profile exposed; $H$, the reflected radiation from the sky; and $T$, the radiation reflected from the terrain. Thus,

$$
L=D+H+T
$$

While a great many data have been collected on the direct and "sky" radiation falling upon a horizontal surface, there is little information available as regards the sunlight reflected from the earth, or the total energy from these 3 sources which falls upon a solid object, such as the human body. The relative importance of the 3 factors, direct, sky, and earth radiation, varies with the position of the man exposed to them. Hence, integrated measurements of the energy from the 3 sources by means of a physical instrument, such as the Vernon sphere, are not directly interpretable in terms of the solar heat load received by a man exposed to the same conditions. The following estimates in which the human body is treated as though made up of simple geometrical surfaces give an idea of the variations of the solar heat load with various conditions, and provide approxi- mate values for comparison with the metabolic heat load.

The direct radiation. Let us designate as $S$, the total energy of all wave lengths contained in sunlight (approximately $0.29 \mu$ to $2.2 \mu$ ) falling on unit area of a surface normal to the sun's rays in unit time. Let $F$ represent the fraction of sunlight diffusely reflected by a fabric or by human skin; the portion of the incident energy absorbed by the clothing or body is then $(1-F) .^{3}$

The direct component of the solar heat load, $D$, is then

$$
D=S(1-F) P
$$

where $P$ is the profile exposed, i.e., the projection of the body shadow on a plane normal to the sun's rays. With the sun directly overhead and the man standing erect, $P$ is equal to about 7 per cent of the body surface or about $0.12 \mathrm{~m}^{2}$ for a man of average body surface, $1.7 \mathrm{~m}^{2}$. For a man lying prone, $P$ is equal to about 30 per cent of the body surface or for an average man, $0.51 \mathrm{~m}^{2}$. As the sun moves away from the zenith, $P$ approaches $0.51 \mathrm{~m}^{2}$ for a man facing the sun, approximately as the sine of the zenith angle. At $15^{\circ}$ from zenith (one hour) the profile presented should be about $0.13 \mathrm{~m}^{2}$, i.e., about the same as when the sun is at zenith. At $60^{\circ}$ from zenith (four hours), however, the profile should be about $0.51 \times \sin 60^{\circ}=0.42 \mathrm{~m}^{2}$.

For a man lying prone $P$ decreases as the cosine of the zenith angle, so that when the sun is at $60^{\circ}$ the profile presented is only one-half as great as when the sun is at zenith, i.e., $0.255 \mathrm{~m}^{2}$. Direct solar heat loads have been calculated on the above basis for $0^{\circ}$ and $60^{\circ}$ zenith angle, and these appear in Table IV. In all calculations in Table IV the values of solar radiation for $20 \mathrm{~mm}$. water vapor, which appear in Table I have been used;

$$
S=\int_{\lambda .20 \mu}^{\lambda 2.2 \mu} S_{\lambda} d \lambda \text {, and } F=\frac{\int_{\lambda .29 \mu}^{\lambda 2.2 \mu} F_{\lambda} S_{\lambda} d \lambda}{S}
$$

when $S_{\lambda}$ and $F_{\lambda}$ are, respectively, the solar energy and the reflection for wavelength $\lambda$. Since $S_{\lambda}$ and $F_{\lambda}$ vary independently with $\lambda$ the numerical value of $D$ in equation (1) depends upon a given set of conditions throughout which the sunlight spectrum varies and the reflection spectrum is different for each fabric, such estimates are only approximate; but the error is certainly not greater than errors introduced by other assumptions that must be made in such an analysis. 
and the reflection factor $F$ taken as 0.43 , the value found by Martin for blond human skin.

Rough as these estimates are, they show clearly that the direct solar heat load must vary considerably with the position of the man and the time of day; and that the maximum direct load may be received in one position at one time of day, and in another position at another time.

The "sky" radiation. Direct measurements show that about 15 per cent of the radiation falling on a horizontal surface when the zenith angle is between $0^{\circ}$ and $60^{\circ}$ is reflected radiation from the sky (see 9, p. 60). The proportion of sky radiation increases rapidly for zenith angles greater than $60^{\circ}$, but between $0^{\circ}$ and $60^{\circ}$ the sky radiation falling on a horizontal surface of unit area should be equal to approximately $\left(\frac{0.15}{1.00-0.15}\right) S \cos z$, where $z$ is the zenith angle. The sky radiation falling on a vertical surface will be only one-half that striking a horizontal surface, since the former presents itself to only one-half the heavens. This makes it difficult to estimate the amount of sky radiation striking an irregular body such as a man. In calculating the heat load we have used one-half the total body surfare for both the erect and prone positions, on the assumption that about half the body is presented horizontally to the sky when prone and that the greater part of the body surface is presented vertically to the sky when erect. Estimates based on these assumptions are presented in Table IV.

TABLE IV

Estimated solar heat load under various conditions

\begin{tabular}{|c|c|c|c|c|c|}
\hline \multirow{2}{*}{$\begin{array}{c}\text { Position } \\
\text { of } \\
\text { man }\end{array}$} & \multirow{2}{*}{$\begin{array}{c}\text { Zenith } \\
\text { angle }\end{array}$} & \multicolumn{4}{|c|}{ Solar heat load ${ }^{2}$} \\
\hline & & $\underset{(D)}{\text { Direct }}$ & $\begin{array}{l}\text { Sky } \\
\text { (H) }\end{array}$ & $\underset{(\mathrm{T})}{\text { Terrain } 2}$ & $\begin{array}{c}\text { Total } \\
\text { (L) }\end{array}$ \\
\hline & & \multicolumn{4}{|c|}{ kilocalories per min. } \\
\hline Erect & $\begin{array}{r}0^{\circ} \\
60^{\circ}\end{array}$ & $\begin{array}{l}0.90 \\
2.67\end{array}$ & $\begin{array}{l}1.13 \\
0.45 \\
x y 4\end{array}$ & $\begin{array}{l}1.88 \\
0.75\end{array}$ & $\begin{array}{l}3.91 \\
3.87\end{array}$ \\
\hline Prone & $\begin{array}{r}0^{\circ} \\
60^{\circ}\end{array}$ & $\begin{array}{l}3.84 \\
1.54\end{array}$ & $\begin{array}{l}1.13 \\
0.45\end{array}$ & $\begin{array}{l}0.78 \\
0.31\end{array}$ & $\begin{array}{l}5.75 \\
2.30\end{array}$ \\
\hline
\end{tabular}

1 Under the following atmospheric conditions, $20 \mathrm{~mm}$. $\mathrm{H}_{2} \mathrm{O}, 2.8 \mathrm{~mm}$. ozone, 300 dust particles per $\mathrm{cm}^{3}$, and assuming that 43 per cent of the total solar radiation is reflected by the body.

2 Albedo of terrain assumed to be $\mathbf{0 . 2 5}$.

The terrain reflection. Estimation of the heat load reflected from the terrain is yet another prob- lem. It is necessary, first, to know the albedo, $A$, or fraction of the solar radiation that is diffusely reflected by the terrain." A good many determinations of the albedos of terrains have been made by visual photometry, and hence can only be accepted as approximate values for total sunlight. For our estimates in Table IV, 25 per cent diffuse reflection has been assumed. This value was obtained for a desert sand by Mr. Irving F. Hand (personal communication). Hulburt (10) obtained somewhat higher values for beach sands. Coblenz found 30 per cent diffuse reflection from the leaves of the tulip tree, but lower values for other foliage. Some high albedos have been obtained for snow, in the ultraviolet and visible, but the infrared is largely absorbed (see 10).

For approximate estimates it may be assumed that the terrain is a surface of infinite area, which reflects 25 per cent of the solar radiation falling on it, including direct and "sky" radiation. A horizontal plane facing this surface will receive per unit area that quantity of radiant energy reflected from a similar area of the reflecting surface; whereas a horizontal plane facing upwards will receive none of the reflected radiation. A vertical plane will receive one-half the radiation received by a horizontal plane facing the reflecting terrain.

If we assume that in the erect position most of the body surface is exposed vertically, we may write

$$
\begin{aligned}
T= & M(1-F) \\
& \times \frac{A\left(S \cos z+\frac{0.15}{1.00-0.15} S \cos z\right)}{2}
\end{aligned}
$$

where $M$ is the portion of the body surface exposed to the diffusely reflected radiation from the terrain. Assuming that all the surface is exposed vertically the value $1.7 \mathrm{~m}^{2}$ may be assigned to $M$. Since any part of the body exposed horizontally facing the earth's surface will receive twice this much reflected radiation from the terrain whereas those that face upward will receive none at all, this assumption seems not too unreasonable.

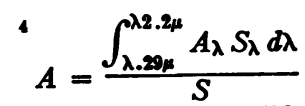

Hence the same qualifications apply as for $S$ and $F$, see footnote 3 . 
In the prone position, the surface presented to the terrain is relatively small. Assuming that a profile $0.5 \mathrm{~m}^{2}$ is in contact with the ground and another equal profile is presented to the sky, 1.0 $\mathrm{m}^{2}$ of the body surface will receive no appreciable amount of reflected radiation from the terrain. The remainder of the body surface, $0.7 \mathrm{~m}^{2}$ may be regarded as presenting a vertical surface, and hence may be substituted for $M$ in equation (3).

In Table IV estimates of the direct, sky, terrain, and total heat loads for the erect and prone positions and for $0^{\circ}$ and $60^{\circ}$ zenith angle, are presented. Reference to this table indicates that, even though considerable errors may have been introduced in estimating the heat loads from the sky and from the terrain, these factors cannot be neglected in the estimation of the total solar heat load. They also show that these factors may be expected to have very different relative importance under different conditions. This alone throws doubt on the possibility of obtaining satisfactory estimates of the solar heat load by means of experiments in which men are exposed to sunlight out of doors.

\section{THE RELATIVE IMPORTANCE OF THE SOLAR HEAT LOAD}

The relative importance of the solar heat load may best be evaluated by comparing it with the heat load of human metabolism. The metabolism of a man of average height and weight is about 96 kilocalories per hour when seated and about 265 kilocalories per hour when marching at 3 miles per hour. For comparative purposes the average of all the values for the total solar heat load presented in Table IV may be used. This is roughly 4 kilocalories per minute or 240 kilocalories per hour. This is 2 to 3 times the resting metabolism, and about equal to the marching metabolism. It would be necessary to evaporate approximately 420 grams of water per hour to take care of the solar heat load of 240 kilocalories. This is about one-half the water requirement of a man marching in the desert in the middle of the day under average summer conditions $(5,11)$.

To what extent may this heat load be decreased by choosing clothing with the best reflection characteristics? The values for the heat load calculated in Table IV are based on reflection of 43 per cent. If the reflection were 71 per cent, as measured by Martin for white cloth, the solar heat load would be about one-half or 120 kilocalories per hour. This would seem to be about the best achievable condition, but would not be compatible with military field requirements. On the other hand, if the reflection were 12 per cent, as found for dark flannel suiting, the solar heat load would be increased to about 370 kilocalories per hour. In terms of evaporation of water, this means a difference of about 420 grams per hour as the range between the best and the worst conditions. As regards military fabrics the limits entailed by the requirements of camouflage, and the nature of fabrics and dyestuffs, the differences between field uniform fabrics in terms of the saving of water by reflection of the solar heat load would probably be much less than this. ${ }^{5}$ Reference to Table I will show that if because of camouflage requirements, the saving must be made principally from the longer wave length infrared, it could not be very great in any case.

\section{EXPERIMENTAL DETERMINATION OF THE EFFECTS OF CLOTHING ON THE SOLAR HEAT LOAD}

Physiological measurements. It is generally assumed that when the air is relatively dry and the ambient temperature is near that of the body's surface, the amount of water evaporated, as measured by the decrease of body weight, provides a measure of the amount of heat which the body has dissipated, within a given time. This is true only when surrounding surfaces and objects are also at the temperature of the body's surface. It does not imply that it is possible accurately to estimate the solar heat load by comparing evaporative losses for men in the sun and in the shade as has been attempted. In the first place, the establishment of adequate shade for such an experiment is difficult, since reflection of sunlight from the sky and from the terrain which remain when the direct sunlight is eliminated are difficult to evaluate. Furthermore, the use of any object for shading the body introduces another factor, the

\footnotetext{
5 The solar heat load may be easily estimated for the various types of clothing described in Table II. The values of $L$ presented in Table IV need only be multiplied by $\frac{\text { percentage reflection }}{43}$.
} 
radiation reemitted by that object, and there are still other factors which need to be taken into consideration.

Under conditions in which the ambient air temperature is below body temperature, heat is lost by convection and conduction, which thus interfere with estimates of the solar heat load. Convection, provided by wind or simply by body movement, may be a factor even when the ambient temperature is above that of the body since it may affect the rate of evaporation on the body surface in the case of porous clothing. The estimation of these factors is beyond the scope of this paper, but they should be considered in any calculation of the total heat load.

Another factor seldom taken into account is the exchange of radiation of longer wave lengths than those found in sunlight, between the body and its surroundings, i.e., the terrain and the atmosphere. To appreciate this phase of the problem let us first consider the exchange between the body and the terrain. For the purpose, the terrain may be assumed to be a diffusely radiating surface of infinite extent, in which case the same geometry applies as for the reflection of sunlight from the terrain (see p. 716). On the basis of the assumptions made above, a man standing erect would present his body surface vertically and would receive one-half the radiation from the terrain. We may thus treat the problem as the exchange of radiation between two surfaces of area equal to one-half the body surface or $0.85 \mathrm{~m}^{2}$. If the air were absolutely dry, these two surfaces might be treated as black body radiators, and the StefanBoltzmann law applied. This law states that the exchange of radiation between two such bodies is proportional to the fourth power of the difference between their absolute temperatures. The magnitude and direction of this heat exchange would depend, upon the temperature of the body surface and that of the terrain. By way of example, if the body surface were at $37^{\circ} \mathrm{C}$. and the terrain at $60^{\circ} \mathrm{C}$. the body of a man standing erect should gain 128 calories per hour from the terrain, a sizeable addition to the total heat load. If the terrain were cooler than the body, the latter would lose heat.

When water vapor is present a certain fraction of this radiation will be absorbed by the atmos- phere lying between the body and the terrain. Black bodies at the temperatures of the human body and the terrain, emit radiation over a broad range with a maximum at about $10 \mu .^{6}$ Water vapor is transparent to a wide spectral band at about this wave length, but strongly absorbs wave lengths on both sides including a large fraction of that radiated by such bodies $(12,13)$. The other gases of the atmosphere do not absorb in the spectral region to which water vapor is transparent, with the exception of ozone which is only present in important concentration in the upper layers of the atmosphere. Because of this specific absorption of certain wave lengths the StefanBoltzmann law is not directly applicable when water vapor is present in the atmosphere, and the estimation of the heat load emitted by the terrain thus involves considerable uncertainty under these conditions. However, since most of the radiation from the terrain which strikes the body comes from the relatively near regions, the effect of absorption by water vapor may not be great.

TABLE V

Reflection by military fabrics of radiation from a black body at $60^{\circ} \mathrm{C}$.

\begin{tabular}{c|c|c|c}
\hline \multicolumn{4}{c}{ Data of Aldrich } \\
\hline \multirow{3}{*}{ Item } & $\begin{array}{c}\text { Contributing to } \\
\text { the heat load }\end{array}$ & Transmitted & Reflected \\
\cline { 2 - 4 } & per cent & per cent & per cent \\
& 87.0 & 4.6 & 13.0 \\
1 & 90.0 & 0.6 & 10.0 \\
2 & 74.8 & 0.6 & 25.2 \\
3 & 75.0 & 2.4 & 25.0 \\
4 & 90.5 & 1.5 & 9.5 \\
5 & 88.5 & 0.0 & 11.5 \\
6 & 90.4 & 0.0 & 9.6 \\
7 & 90.0 & 0.0 & 10.0 \\
8 & 81.0 & 0.0 & 19.0 \\
9 & 90.0 & 0.0 & 9.1 \\
10 & & & \\
\hline
\end{tabular}

1 The transmitted radiation is considered to be absorbed since it will be largely absorbed by the skin.

It is improbable that the heat load received by such radiation from the terrain can be reduced appreciably by choice of fabrics. Aldrich has made measurements of the reflection by those military fabrics listed in Tables II and III of radiation from a body at $60^{\circ} \mathrm{C}$.; these are presented in Table V. Very little of such radiation is reflected by any of the fabrics.

- The distribution is described by Planck's equation. 
Radiation exchange exclusive of sunlight, between the body and the atmosphere involves the same factors, but is even more complex. The transparency of water vapor permits some of the radiation from the body to pass to higher layers of the atmosphere which are cooler than the ambient layer. This is a channel of heat loss usually disregarded. Accurate estimate of this radiant energy loss is difficult, but an idea of its relative magnitude may be gained from an analysis made by Simpson $(14,15)$ for an entirely different purpose. In considering the heat loss from the earth, this investigator (15) estimates maximum and minimum values for atmospheric transmission taking differences in amount of water vapor into account, and arrives at mean and limiting values for the long wave-length radiant energy lost to the heavens by a horizontal surface at a given temperature (Figure 2). This is generally known as

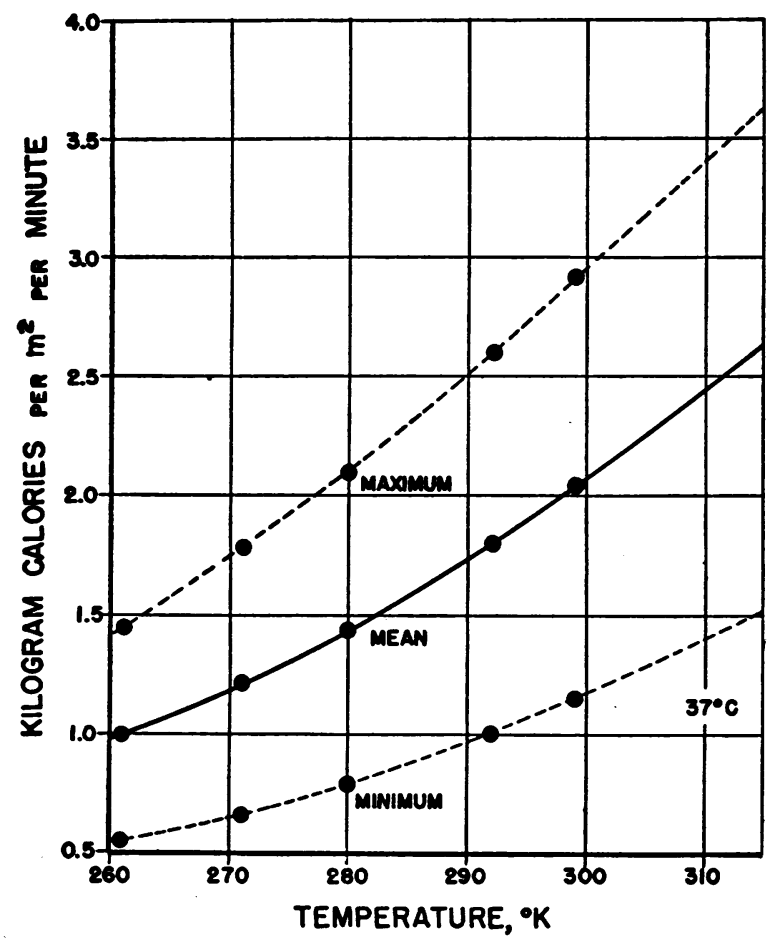

Fig. 2. Estimated Radiation Loss from a Horizontal Surface to the Atmosphere

From the data of Simpson (15).

the "nocturnal" radiation because it is usually measured at night. The out-going radiation measured independently of solar radiation during the day is comparable, and is dependent chiefly on the temperature and humidity (16). Measurements by different methods $(17,18)$ give values falling within Simpson's estimates.

Extrapolating Simpson's mean curve (Figure 2) we see that a surface at $37^{\circ} \mathrm{C}$. may be expected to lose about 2.5 kilocalories per m. ${ }^{2}$ per minute by this channel. Using the same treatment as for solar radiation reflected from the sky a man standing erect would present $1.7 \mathrm{~m}^{2}$ vertically to the heavens and should lose about 128 kilocalories per hour as long wave length radiation. This might be considerably higher or lower depending on the amount of water vapor in the atmosphere.

For purely illustrative purposes, a thermodynamic balance sheet has been attempted in Table VI, for a hypothetical set of conditions, namely;

TABLE VI

Attempted thermodynamic balance sheet for a man marching at 3 miles per hour; ambient air dry with temperature about $37^{\circ} \mathrm{C}$., terrain at $60^{\circ} \mathrm{C}$., and body surface at $37^{\circ} \mathrm{C}$. Sun at zenith

Metabolism

Total solar heat load

Long wavelength radiation

exchange with terrain
Long wavelength radiation

kilocalories per hour

exchange with heavens
Evaporation

Evaporation
Convection and conduction

$$
\begin{aligned}
& +265 \\
& +234 \\
& +128 \\
& -128 \\
& -506^{1} \\
& \pm ?
\end{aligned}
$$
Total $\overline{-7 \pm ?}$ (this close appar-
ent balance is fortuitous)

1 Based on average value from Adolph et al. (11), 882 grams of water loss per hour.

sun at zenith, temperature of the terrain $60^{\circ} \mathrm{C}$., ambient air relatively dry and at a temperature somewhat above that of the body, the man erect, marching at 3 miles per hour. The evaporation factor is based on the loss of 882 grams of water per hour, an average figure obtained (11) for men walking on the desert. Convection and conduction losses are assumed to be small because the temperature of the ambient air is near that of the body, but represent an unknown value. The radiation values are those calculated in this paper.

The close over-all balance obtained is fortuitous, as is the exact balance between radiation from the terrain and to the heavens. Had the ground temperature been taken as $10^{\circ}$ lower or the assumption made that the sun had warmed the clothing 
to a temperature $10^{\circ}$ higher than that chosen, the balance would be considerably upset. It should be pointed out that for a man at rest, the long wave length radiation exchange would be more important relative to the metabolism, and it might be interesting to explore other possibilities. However, Table VI shows clearly that a balance is possible with values of these magnitudes, but that none of the various items estimated therein can be neglected in drawing up a balance sheet.

The evaporation factor tends to adjust itself due to sweating so that the body temperature does not rise excessively. Thus this factor may be expected to vary to compensate when the other factors shift with various conditions. When the magnitude and variability of the other factors are considered, it does not seem surprising that Adolph and his coworkers $(5,11)$, should have obtained different values for evaporative heat loss under the various conditions they explored, nor that these values display the general consistency they do.

The whole problem of radiant exchange with outdoor surroundings is, thus, quite complex and cannot be accurately simulated in an enclosed room. Moreover, all these factors render physiological measurements out-of-doors subject to considerable variability, not only in so far as the solar heat load is concerned, but with regard to the heat load as a whole.

Physical measurements. Physical measurements would seem better than physiological for determining protection afforded by clothing against solar heat load, since the important factor to be measured is the diffuse reflection of solar radiation. Such measurements must either be made with sunlight, as were those of Aldrich and Martin, or must involve measurements throughout the spectrum. If sunlight is used, conditions should be selected such that its intensity and spectrum can be estimated with reasonable accuracy. The data of Moon (1) should be useful in this respect. Spectral measurements must cover the range $0.029 \mu$ to $2.2 \mu$. All such measurements should be based on the response of thermocouple or bolometer. Determinations made by photometric methods would have little meaning, since they only give an index of the reflection in the visible in terms of the human eye. Since the fabrics may transmit a certain small fraction of the incident light, which will in turn be absorbed or reflected by the underclothing or skin, the fabric to be tested should be backed with underclothing and/or a surface resembling human skin.

\section{CONCLUSIONS}

Since the amount of saving of solar heat load to be anticipated by improvement of the reflecting properties of military uniform fabrics is not great, it would seem wise to concentrate effort on the evaluation of properties of fabrics that can be studied in the laboratory, and which are of importance under all conditions of hot environment, namely, their effect on cooling by conduction, convection, and radiation at ordinary temperatures.

Where reflecting properties of clothing are to be considered, they should be determined by direct physical measurement.

Necessary data are lacking for evaluation of the thermal relationships of man with an outdoor environment, some of which lie in a domain that is generally left to the physicist, the meteorologist, or the astronomer. It would seem important to obtain some of these data with the express problems of the environmental physiologist and climatologist in mind.

\section{SUM MARY}

1. The solar heat load received by man is estimated and compared with the metabolic heat load.

2. Methods of determining the effect of clothing on the solar heat load are considered.

a. Physiological determinations either indoors or out-of-doors are not trustworthy. It is impossible to simulate accurately in the laboratory, either sunlight or the conditions of exposure to sunlight. The variables entering into outdoor experiments render them susceptible to misinterpretation.

b. Physical measurements of the reflection of sunlight by fabrics should give the best estimates of their effectiveness in combatting solar heat load.

3. The saving of solar heat load to be accomplished under the limitations of camouflage requirements for military clothing may not justify the time and effort needed to make extensive studies. 
Most of the values for reflection of sunlight by fabrics used in this report were obtained by Dr. L. B. Aldrich of the Smithsonian Institution of Washington at the request of Dr. F. B. Wulsin of the Military Planning Division, Office of the Quartermaster General. Albedo measurements of terrain made by $\mathrm{Mr}$. Irving $\mathrm{F}$. Hand of the U. S. Weather Bureau have also been employed. It is a pleasure to acknowledge the cooperation of these men in placing their material at my disposal. Thanks are also due to Professors L. H. Newburgh and C. P. Yaglou, and to Commander R. H. Lee, H-V(S), USNR, for advice and criticism.

\section{BIBLIOGRAPHY}

1. Moon, P., Proposed standard solar-radiation curves for engineering use. J. Franklin Inst., 1940, 230, 583.

2. Wulsin, F. R., Responses of man to a hot environment. Report, Climatic Research Unit, Research and Development Branch, Military Planning Division, O. Q. M. G., 1943, 1-59.

3. Martin, C. J., Thermal adjustment of man and animals to external conditions. Lancet, 1930, 219, 673.

4. Coblenz, W. W., The diffuse reflecting power of various substances. Bull. Bureau of Standards, 1913, 9, 283.

5. Adolph, E. F., Personal communication.

6. Schultze, W., reflexion und Absorption der Haut im sichtbaren Spectrum. Strahlentherapie, 1926, 22, 38.

7. Schultze, W., Die Reflexion und Absorption der menschlichen Haut im Ultraviolett. Strahlentherapie, 1930, 35, 369.
8. Hardy, J. D., and Muschenheimer, C., The radiation of heat from the human body. IV. The emission, reflection, and transmission of infrared radiation by the human skin. J. Clin. Invest., 1934, 13, 817.

9. Laurens, H., The Physiological Effects of Radiant Energy. Chem. Catalogue Co., New York, 1933.

10. Hulburt, E. O., The ultraviolet, visible, and infrared reflectivities of snow, sand, and other substances. J. Optical Soc. America, 1928, 17, 23.

11. Adolph, E. F., Rahn, H., Gosselin, R. E., Goddard, D. R., Brown, H. H., Kelly, J. J., and Wolf, A. F., Personal communication.

12. Humphreys, C. E., Physics of the Air. McGraw-Hill, New York, 1940. Chapter VI.

13. Kuiper, G. P., Stellar temperature. In Temperature, its Measurement and Control in Science and Industry. Reinhold Publishing Corp., New York, 1941.

14. Simpson, G. C., Some studies in terrestrial radiation. Mem. Roy. Meteorological Soc. (London), 1928, 2, 69.

15. Simpson, G. C., Further studies in terrestrial radiation. Mem. Roy. Meteorological Soc. (London), 1928, 3, 1.

16. Angström, A., Measurement and registration of the outgoing effective temperature radiation. Arkiv $f$. Mathematik Astronomi och Fysik., 1929, 22B, 1.

17. Dines, W. H., and Dines, L. H. G., Monthly mean values of radiation from various parts of the sky at Benson, Oxfordshire. Mem. Roy. Meteorological Soc. (London), 1927, $2,1$.

18. Ångström, A., A study of radiation of the atmosphere based upon observations of the nocturnal radiation during expeditions to Algeria and to California. Smith. Misc. Call., 1915, 65, 1. 